\title{
Growth Kinetics and Toxicity of Pseudomonas fredriksbergsis Grown on Phenol as Sole Carbon Source
}

\author{
Salah H. Aljbour ${ }^{*}$, Khaled M. Khleifat ${ }^{2}$, Amjad Al Tarawneh ${ }^{3}$, Batool Asasfeh², \\ Haitham Qaralleh" ${ }^{4}$, Tayel El-Hasan ${ }^{5}$, Mousa K. Magharbeh ${ }^{6}$, Muhamad O. Al-Limoun ${ }^{2}$ \\ 1 Chemical Engineering Department, College of Engineering, Mutah University, Karak, 61710, Jordan \\ 2 Biology Department, College of Science, Mutah University, Mutah, Karak, 61710, Jordan \\ 3 Prince Faisal Center for Dead Sea, Environmental and Energy Research, Mutah University, Karak, 61710, \\ Jordan \\ 4 Department of Medical Laboratory Analysis, College of Science, Mutah University, Mutah, Karak, 61710, \\ Jordan \\ 5 Department of Chemistry, College of Science, Mutah University, Karak, 61710, Jordan \\ 6 Department of Pharmaceutical Chemistry, Faculty of Pharmacy, Mutah University, Karak, 61710, Jordan \\ * Corresponding author's e-mail: saljbour@mutah.edu.jo
}

\begin{abstract}
Phenol is one of the main pollutants that have a serious impact on the environment and can even be very critical to human health. The biodegradation of phenol can be considered an increasingly important pollution control process. In this study, the degradation of phenol by Pseudomonas fredriksbergsis was investigated for the first time under different growth conditions. Six different initial concentrations of phenol were used as the primary substrate. Culture conditions had an important effect on these cells' ability to biodegrade phenol. The best growth of this organism and its highest biodegradation level of phenol were noticed at $\mathrm{pH} 7$, temperature $28{ }^{\circ} \mathrm{C}$, and periods of 36 and $96 \mathrm{~h}$, respectively. The highest biodegradation rate was perceived at $700 \mathrm{mg} / \mathrm{L}$ initial phenol concentration. Approximately $90 \%$ of the phenol $(700 \mathrm{mg} / \mathrm{L})$ was removed in less than 96 hours of incubation time. It was found that the Haldane model best fitted the relationship between the specific growth rate and the initial phenol concentration, whereas the phenol biodegradation profiles time could be adequately described by the modified Gompertz model. The parameters of the Haldane equation are: $0.062 \mathrm{~h}^{-1}, 11 \mathrm{ppm}$, and $121 \mathrm{ppm}$ for Haldane's maximum specific growth rate, the half-saturation coefficient, and the Haldane's growth kinetics inhibition coefficient, respectively. The Haldane equation fitted the experimental data by minimizing the sum of squared error (SSR) to $1.36 \times 10^{-3}$.
\end{abstract}

Keywords: phenol, biodegradation, P. fredriksbergsis, Haldane model, GC-MS

\section{INTRODUCTION}

All living things need to use chemicals as sources of carbon or energy. However, the adaptation of cells to digest these chemicals on earth has been widely acknowledged throughout the ages, but man is accountable for the environmental problem by producing numerous organic species that are resistant to living organisms, particularly microorganisms. Phenol is one of the main pollutants that have a serious impact on the environment and can even be very critical to human health. Phenol compounds are widely used as raw materials for various chemical industries. (Khleifat et al. 2006a; Wen et al. 2020; Zang et al. 2021). Phenol is toxic to some aquatic organisms even at lower concentrations and led to problems in drinking water, such as taste and odor (Khleifat et al. 2007; Rai et al. 2021). Therefore, the US Environmental Protection Agency (EPA) included phenolic compounds on its list of priority pollutants owing to their potential toxicity (Aisami et al. 2020; Gong et al. 2021). Direct inhalation and skin ingestion of phenol may lead to death orally 
due to penetration into the skin and rapid absorption, in addition to being a carcinogen (Khleifat et al. 2006b; Abboud et al. 2007; Wen et al. 2020; Swain et al. 2021).

Abundant processes as chemical or physical techniques have been used for phenol removal such as chemical oxidation, ion exchange; liquidliquid extraction, activated carbon adsorption, incineration and abiotic treatment procedure bear serious drawbacks such as their need for large efforts, costly and the production of unpredictable harmful byproducts (Tomei et al. 2021). Besides, most of these processes do not degrade phenol, but rather transform it into other compounds (secondary pollutants), which can be more dangerous by-products. On the other hand, removing phenol using live cells (biodegradation) is an alternative option and is more cost-effective and environmentally friendly. Thus, the biodegradation of phenol can be considered an increasingly important pollution control process (Khleifat et al. 2008; Liu et al. 2009; El-Naas et al. 2010; Abboud et al. 2010). Biodegradation is generally considered more favorable because of reduced costs and complete mineralization. There is much debate regarding whether possible or not to use natural or genetically engineered microorganisms (GEM) in the biodegrading processes. Government agencies often unfavorable to unleash GEMs environmentally due to the possibility of unforeseen environmental impacts (Khleifat et al. 2008; Liu et al. 2009; Kanavaki et al. 2021). There is still substantial interest in isolation of bacteria that are able to use high concentrations of aromatic compounds as growth substrate, (Khleifat 2007; Adetitun et al. 2021), as the phenol compound that has been studied here. It has been stated that the degradation mode of catechol, the availability of carbon and nitrogen sources, the toxins presence and some physical parameters such as temperature may affect bacterial growth using phenol as sole carbon and energy sources (El-Naas et al. 2010; Malhotra et al. 2021).

In contrast, utilization of phenol or other aromatic compounds by Pseudomonas fredriksbergsis as growth substrates has not been reported. The bacterium, Pseudomonas fredriksbergsis used in the current study was isolated from the Al-Ghweir Agricultural Station, Karak, Jordan. It was identified by means of $16 \mathrm{~S}$ rRNA techniques. The nucleotide accession number in Genbank was MN083294. It is Gram-negative, motile, nonspore-forming rods (Andersen et al. 2000).
It was found to be positive for nitrogen fixation and phosphate solubilization. In this study, the degradation of phenol by $P$. fredriksbergsis was investigated for the first time under different growth conditions, including substrate concentration, $\mathrm{pH}$ and incubation temperature. In addition, mathematical modeling was used for studying the kinetics of bacterial growth on phenol besides the biodegradation kinetics of phenol by the same bacteria.

\section{EXPERIMENTAL}

\section{Bacterial strain}

The bacterium used in the current study was Pseudomonas fredriksbergsis bacterial strain, which was isolated from the Al-Ghweir Agricultural Station, Al-Karak, Jordan. It was identified by using 16S rRNA techniques through Anna Rosa Sprocati, Rome, Italy. The nucleotide accession number in Genbank was (MN083294). The morphological characteristics were always being microscopically checked and its biochemical identity was reverified using the REMEL kit (RapIDONE and RapID NF plus systems) procedure (Tarawneh et al. 2009; Althunibat et al. 2016; Al-Asoufi et al. 2017).

\section{Preparation of mineral medium with phenol}

In order, to prepare this media; three solutions were prepared separately: (a), Phenol solution was prepared by dissolving $5 \mathrm{~g}$ in 200 $\mathrm{ml}$ de-ionized water (the final concentration was $25,000 \mathrm{ppm}$ ). To avoid any possible temperature effect on phenol, this solution was filter sterilized. (b), Mineral media; It was prepared by dissolving the following ingredients in 1000 ml Erlenmeyer flask: $1 \mathrm{~g} \mathrm{~K}_{2} \mathrm{HPO}_{4}, 1 \mathrm{~g} \mathrm{NH}_{4} \mathrm{NO}_{3}$,

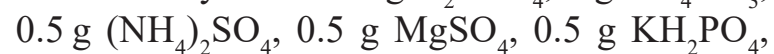
$0.5 \mathrm{~g} \mathrm{NaCl}, 0.02 \mathrm{~g} \mathrm{CaCl}_{2}, 0.02 \mathrm{~g} \mathrm{FeSO}_{4}$. The media was then distributed in $125-\mathrm{ml}$ Erlenmeyer flasks containing the proper volume of mineral medium according to the phenol concentration needed and then autoclaving was made. (c), Wolfe's mineral solution, it was prepared by dissolving $1.5 \mathrm{~g}$ of nitrilotriacetic acid in $500 \mathrm{~mL}$ de-ionized water in $1000 \mathrm{ml}$ Erlenmeyer flask, the $\mathrm{pH}$ was adjusted by $\mathrm{KOH}$ to 6.5 to achieve the best solubility. Then the followings were added: $3 \mathrm{~g} \mathrm{MgSO}_{4} \cdot 7 \mathrm{H}_{2} \mathrm{O}, 1 \mathrm{~g} \mathrm{NaCl}, 0.5 \mathrm{~g} \mathrm{MnSO}_{4} \cdot \mathrm{H}_{2} \mathrm{O}$, $1 \mathrm{~g} \mathrm{FeSO}_{4} \cdot 7 \mathrm{H}_{2} \mathrm{O}, 0.1 \mathrm{~g} \mathrm{CoCl} \cdot 6 \mathrm{H}_{2} \mathrm{O}, 0.1 \mathrm{~g}$ 
$\mathrm{CaCl}_{2}, 0.1 \mathrm{~g} \mathrm{ZnSO}_{4} \cdot 7 \mathrm{H}_{2} \mathrm{O}, 0.01 \mathrm{~g} \mathrm{CuSO}_{4} \cdot 5 \mathrm{H}_{2} \mathrm{O}$, $0.01 \mathrm{~g} \mathrm{AlK}\left(\mathrm{SO}_{4}\right)_{2} \cdot 12 \mathrm{H}_{2} \mathrm{O}, 0.01 \mathrm{~g} \mathrm{H}_{3} \mathrm{BO}_{3}, 0.01 \mathrm{~g}$ $\mathrm{Na}_{2} \mathrm{MoO}_{4} \cdot 2 \mathrm{H}_{2} \mathrm{O}$. The volume was then completed to the mark with distilled water and shake vigorously followed by sterilization using filter. Finally, the mineral media with phenol was prepared by adding $0.5 \mathrm{ml}$ Wolfe's and proper phenol volume to each flask based on the wanted phenol concentration. For example to achieve mineral media with 200-ppm phenol concentration, $0.5 \mathrm{ml}$ wolfe's solution and $0.4 \mathrm{ml}$ phenol solution were added to the $49.1 \mathrm{ml}$ mineral media. Moreover, for the $700 \mathrm{ppm}$; $0.5 \mathrm{ml}$ Wolfe's solution and $1.4 \mathrm{ml}$ phenol solution were added to the $48.1 \mathrm{ml}$ mineral media.

\section{Growth assessment and phenol degradation}

P. fredriksbergsis ability to grow on phenol (as a sole source of carbon) was studied by growing $P$. fredriksbergsisin TSB to the middle of exponential phase (OD at $600 \mathrm{~nm} \approx 0.50$ ). The bacterial cells were harvested at $4000 \mathrm{rpm}$ for $15 \mathrm{~min}$ by centrifuge. The OD was adjusted to 0.2 at 600 $\mathrm{nm}$ to be used later as an inoculum by washing and suspend the cells with mineral media (Qaralleh et al. 2019). Mineral media with 700-ppm phenol concentration was prepared and inoculated with $P$. fredriksbergsis. The bacterial growth behavior was monitored spectrophotometry at $600 \mathrm{~nm}$ for 12, 24, 36, 48, 60, 72, 84, and $96 \mathrm{hrs}$. Same procedure was carried out for the control (mineral media with $700 \mathrm{ppm}$ phenol and without bacterial inoculation).

\section{Phenol assay procedure}

The 4-aminoantipyrine colorimetric method was used to determine phenol concentration (Der Yang and Humphrey 1975). Ammonium hydroxide $(0.5 \mathrm{~N})$ was supplemented and stirred well. The adjustment of $\mathrm{pH} 7.9 \pm$ 0.1 was made by adding potassium phosphate buffer, $\mathrm{pH}$ of 6.8 pursued by adding $2 \% \mathrm{w} / \mathrm{v}$ 4 -aminoantipyrine and $8 \%$, w/v potassium ferricyanide. Specimens were left for $15 \mathrm{~min}$ at room temperature to achieve the completion of reaction and measuring the absorbance at $510 \mathrm{~nm}$ was conducted by using single beam of UV-Vis Spectrophotometer. Standard curve was calibrated to elicit the concentration of phenol using congruent recorded absorbance through using spectrophotometer.

\section{Effect of $\mathrm{pH}$ and temperature on phenol degradation}

The ability of $P$. fredriksbergsis to degrade phenol was examined in $700 \mathrm{ppm}$ phenol concentration which, prepared in mineral media $P$. fredriksbergsis were cultured under different parameters using shaking incubator in the mineral media. The influence of $\mathrm{pH}$ on the degradation of phenol by $P$. fredriksbergsis was investigated using four different $\mathrm{pH}$ values $(5.5,7,8$, and 9). Furthermore, the influence of different temperatures $\left(25,28,33\right.$, and $\left.37^{\circ} \mathrm{C}\right)$ on phenol degradation was studied.

\section{MATHEMATICAL MODELING}

The logistic equation is widely used to describe the $P$. fredriksbergsis growth profile of biomass in a batch system with both exponential and stationary phases. The differential form of the logistic equation is given as follows:

$$
\frac{d X}{d t}=\mu_{m} X\left(1-\frac{X}{X_{m}}\right)
$$

where: $\mu_{m}$ is the maximum specific growth rate $\left(\mathrm{h}^{-1}\right)$ in a given environment and $X_{m}$ is the maximum cell concentration achievable in that environment $\left(\mathrm{OD}_{600}\right)$.

An integration of the logistic equation yields the following equation for the cell concentration:

$$
X=\frac{X_{o} e^{\mu_{m} t}}{1-\left(\frac{x_{0}}{x_{m}}\right)\left(1-e^{\mu_{m} t}\right)}
$$

where: $X_{0}$ is the initial cell concentration $\left(\mathrm{OD}_{600}\right)$.

Several kinetics models have been developed to describe the relationship between the specific growth rate $\mu$ and substrate concentration, $S$. At high concentrations of substrate, and in case that the growth is affected by inhibitor concentration, Haldane equation is the most widely used inhibition expression:

$$
\mu=\frac{\mu_{\max } S}{K_{s}+S+\frac{S^{2}}{K_{I}}}
$$

where: $\mu_{\max }$ is Haldane's maximum specific growth rate $\left(\mathrm{h}^{-1}\right), K_{I}$ is Haldane's growth kinetics inhibition coefficient (ppm) and $K_{S}$ is the half saturation coefficient (ppm). 
Phenol degradation was simulated by using the modified Gombertz model (Wen et al. 2020):

$$
S=S_{o}\left\{1-\exp \left\{-\exp \left[\frac{R_{m}}{S_{o}} e(\lambda-t)+1\right]\right\}\right\}
$$

where: $S_{0}$ is the initial phenol concentration (ppm), $R_{m}$ is the maximum phenol degradation rate $(\mathrm{ppm} / \mathrm{h})$, and $\lambda$ is the lag phase time (h).

\section{RESULTS AND DISCUSSIONS}

\section{Biodegradation of phenol versus growth of $P$. fredriksbergsis}

In the current investigation, phenol degrading bacterium Pseudomonas fredriksbergsis is isolated from Al-Ghweir Agricultural Station, Jordan and used for the biodegradation of phenol. It was identified by $16 \mathrm{~S}$ rDNA. To guarantee the use of phenol as carbon and energy sources for this bacterium, the phenol minimal medium was implied via having this compound as only carbon and energy sources. Thus the formation of any bacterial biomass will be a function of exhaustion of these substrates (Wang and Loh 1999; Khleifat et al. 2007; Nandy et al. 2021; Khleifat et al. 2006b). The uninoculated phenol-containing culture and the heat-killed suspensions were used as negative controls to assess the biodegradability of phenol. There was no biodegradation activity shown verifying the biodegrading activity made by Pseudomonas fredriksbergsis. Our results showed that P. fredriksbergsis could use phenol compound as carbon and energy sources with different extents (Table 1). The impact of substrate concentration, incubation temperature, and growth media $\mathrm{pH}$ on phenol biodegradation by $P$. fredriksbergsis was investigated.

Table 1. Effect of phenol concentration on the biodegradation rate by $P$. fredriksbergensis

\begin{tabular}{|c|c|c|}
\hline $\begin{array}{c}\text { Concentration } \\
(\mathrm{ppm})\end{array}$ & $\begin{array}{c}\text { Biodegradation } \\
\text { rate (ppm/h) }\end{array}$ & $\begin{array}{c}\text { Percentage removal of } \\
\text { phenol (\%) }\end{array}$ \\
\hline 200 & 1.53 & $32 \%$ \\
\hline 400 & 5.56 & $31 \%$ \\
\hline 700 & 8.33 & $38 \%$ \\
\hline 800 & 6.48 & $18 \%$ \\
\hline 1000 & 5.56 & $27 \%$ \\
\hline 1200 & 4.16 & $16 \%$ \\
\hline
\end{tabular}

\section{Growth kinetics of the isolated strain for phenol biodegradation}

Six different concentrations of phenol were used as the primary substrate (Fig. 1). The experimental biomass growth profiles at different initial phenol concentrations were fitted to the logistic equation by means of non-linear regression technique. Minimization of the sum of the squared error (SSR) by using the Solver add-in in Microsoft Excel 2007 were carried out to obtain the model fitting parameters. Figure 1 shows the logistic model profiles along with the experimental data at different initial phenol concentrations. It can be noticed that at initial phenol concentration of 700 ppm, the biomass growth approached the maximum stationary population size.

On the other hand, at initial phenol concentration of $200 \mathrm{ppm}$, the biomass possessed the highest specific growth rate $\left(\mu_{m}\right)$. At initial phenol concentration of $1200 \mathrm{ppm}$, biomass growth was characterized by slow growth rate and low stationary population size (Table 2).

The determination of the specific growth rate $(\mu)$ for the different initial phenol concentrations were obtained by plotting the biomass growth data during the exponential phase. The specific growth rate $(\mu)$ equals the slope obtained by plotting $\ln \frac{X}{X_{0}}$ versus time. Haldane equation gave an excellent representation of the relationship between the specific growth rate and the initial phenol concentration (Figure 2).

The Haldane's parameters are estimated by means of non-linear regression technique based on minimization of SSR. The parameters of the Haldane equation are: $0.062 \mathrm{~h}^{-1}, 11 \mathrm{ppm}$, and 121 ppm for Haldane's maximum specific growth rate, the half-saturation coefficient, and the Haldane's growth kinetics inhibition coefficient, respectively (Table 3 ). The Haldane equation fitted the experimental data with SSR of $1.36 \times 10^{-3}$. Figure 2 shows a typical trend for the growth kinetics data of an inhibitory substrate. The results indicate that the value of the specific growth rate increases with increasing phenol concentration up to approximately $200 \mathrm{ppm}$, then it starts decreasing with the increase in the initial phenol concentration. The Haldane's maximum specific growth rate reported in this study is comparable to those values reported in literature for phenol biodegradation in several bacterial media. The half-saturation coefficient (11 ppm) as obtained by the Haldane model indicates that phenol concentration 


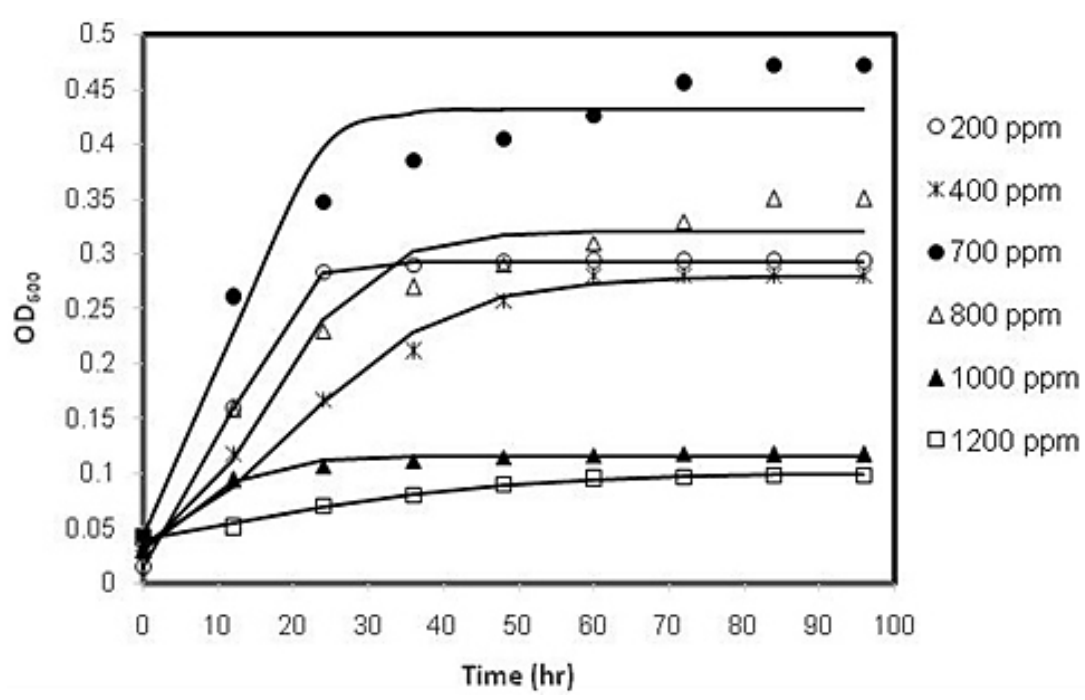

Figure 1. Growth profile of the isolate $P$. fredriksbergensisat different initial concentrations of phenol

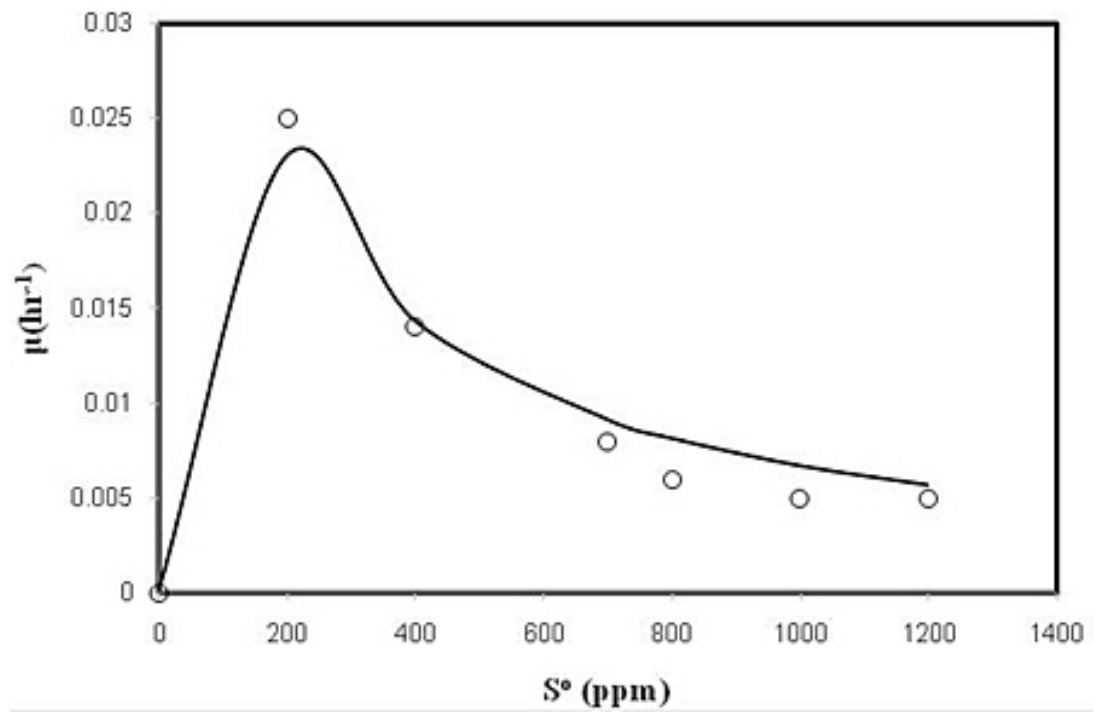

Figure 2. Haldane growth kinetic model fitted to experimental batch growth data of the strain P. fredriksbergensis

Table 2. Logistic growth kinetic parameters for phenol biodegradation by P.fredriksbergensis.

\begin{tabular}{|c|c|c|c|}
\hline Phenol concentration $(\mathrm{ppm})$ & $\mu_{m}\left(\mathrm{~h}^{-1}\right)$ & $X_{m}\left(\mathrm{OD}_{600}\right)$ & $\mathrm{SSR}$ \\
\hline 200 & 0.263 & 0.292 & $1.04 \times 10^{-5}$ \\
\hline 400 & 0.096 & 0.279 & $1.34 \times 10^{-3}$ \\
\hline 700 & 0.194 & 0.432 & $9.80 \times 10^{-3}$ \\
\hline 800 & 0.141 & 0.321 & $5.80 \times 10^{-3}$ \\
\hline 1000 & 0.204 & 0.115 & $5.99 \times 10^{-5}$ \\
\hline 1200 & 0.050 & 0.101 & $3.00 \times 10^{-5}$ \\
\hline
\end{tabular}

must be low to get the specific growth rate equals half the maximum specific growth rate. The Haldane's growth kinetics inhibition coefficient represents a measure of biomass sensitivity to inhibition by inhibitory substances. The value of inhibition constant (121 ppm) indicates that phenol has an appreciated inhibition effect on biomass growth.
Phenol biodegradation profiles were fitted very well into the modified Gombertz model. The fitting parameters of the model are shown in Table 4. At lower initial phenol concentrations, the rate of phenol biodegradation increases with increasing the initial concentration. The maximum phenol biodegradation rate $(10.626$ 
$\mathrm{ppm} / \mathrm{h}$ ) was obtained at an initial phenol concentration of $700 \mathrm{ppm}$. However, at higher initial phenol concentrations, the rate of phenol biodegradation tends to be constant. Therefore, based on growth profile and percentage of phenol removal, the $700 \mathrm{ppm}$ was taken for further experiments (Figures 1 and 3).

\section{Effect of incubation temperature}

The effects of four different incubation temperatures $\left(25,28,33\right.$, and $\left.37^{\circ} \mathrm{C}\right)$ on phenol biodegradation were examined. The amount of phenol degradation varied significantly depending on incubation temperatures, according to the findings of the experiments (Table 5). It is evident that the temperature factor was characterized by being vital when it was less than $28{ }^{\circ} \mathrm{C}$, and that any additional rise in temperature above $33{ }^{\circ} \mathrm{C}$ led to a decrease in growth at $700 \mathrm{ppm}$ phenol. The incubation temperature was found to have a clear effect on the level of cellular mass formation, as is also evident on the phenol degradation rate. Thus, it turns out that phenol degradation biologically appears to occur at room temperature, where it becomes $28{ }^{\circ} \mathrm{C}$ is the optimum temperature for $P$. fredriksbergsis cells. It was mentioned that temperature exhibited a physiologically strong influence on the fate of the phenol compound(Khleifat et al. 2006b; Khleifat et al. 2006a; Abboud et al. 2010). As the average temperature $\left(28^{\circ} \mathrm{C}\right)$ turned out to be the best environmental factor for phenol degradation, or this may be especially due to the influence of temperature on the activities of the enzyme(s) responsible for it(Leven and Schnürer 2005). It has been confirmed that temperature may play an equal or even greater function than the availability of nutrients during the degradation of organic compounds including phenol (Margesin and Schinner 1997; Khleifat and Abboud 2003; Onysko et al. 2000; Lin and Gu 2021).

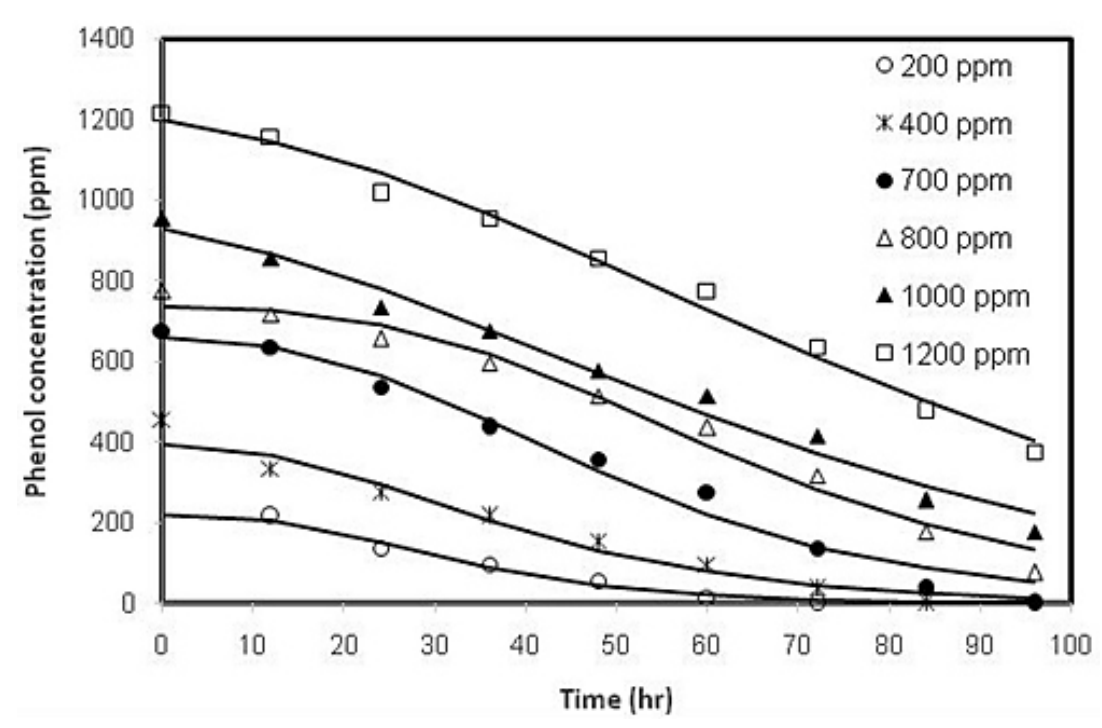

Figure 3. Fitting of $P$. fredriksbergensis growth at different concentrations $(\mathrm{mg} / \mathrm{L})$ of phenol using the modified Gompertz model

Table 3. Haldane's model parameters for the biodegradation of phenol by different bacteria

\begin{tabular}{|l|c|c|c|c|c|}
\hline \multicolumn{1}{|c|}{ Microbial Strain } & $S_{o}(\mathrm{ppm})$ & $\mu_{\max }\left(\mathrm{h}^{-1}\right)$ & $K_{S}(\mathrm{ppm})$ & $K_{l}(\mathrm{ppm})$ & Reference \\
\hline P. fredriksbergensis & $200-1200$ & 0.062 & 11 & 121 & This study \\
\hline Pseudomonas putida & $300-1000$ & 0.031 & 63.9 & 450 & (Bakhshi et al. 2011) \\
\hline Pseudomonas sp. & $100-800$ & 0.464 & 113.5 & 376.7 & (Saravanan et al. 2011) \\
\hline Mixed & $0-800$ & 0.26 & 25.4 & 173 & (Pawlowsky and Howell 1973) \\
\hline Acinetobacter calcoaceticus & $60-500$ & 0.542 & 36.2 & 145 & (Kumaran and Paruchuri 1997) \\
\hline Pseudomonas WUST-C1 & $0-1600$ & 2.5 & 48.7 & 100.6 & (Liu et al. 2013) \\
\hline Pseudomonas putida & $25-800$ & 0.900 & 6.93 & 284.3 & (Wang and Loh 1999) \\
\hline
\end{tabular}


Table 4. Parameters using the Gompertz model on the different concentrations of phenol substrate

\begin{tabular}{|c|c|c|}
\hline $\begin{array}{c}\text { Phenol concentration } \\
(\mathrm{ppm})\end{array}$ & $R_{m}(\mathrm{ppm} / \mathrm{h})$ & $\lambda(\mathrm{h})$ \\
\hline 200 & 5.447 & 11.0 \\
\hline 400 & 7.445 & 10.0 \\
\hline 700 & 10.626 & 16.3 \\
\hline 800 & 9.942 & 25.2 \\
\hline 1000 & 9.073 & 1.9 \\
\hline 1200 & 10.191 & 9.7 \\
\hline
\end{tabular}

\section{Effect of $\mathrm{pH}$ on biodegradation of phenol}

When studying the $\mathrm{pH}$ conditions, the uninoculated culture was used as a biological control to ensure that the phenol drop was caused by a chemical reaction or because of something else. The $\mathrm{pH}$ factor, when tested, was found to have an effect on the amount of phenol within the uninoculated culture. Table 5 gives the biodegradation rate of phenol by P. fredriksbergensis under different growth conditions. P. fredriksbergsis cells performed preferably for biological breakdown of phenol and growth biomass at $\mathrm{pH}$ 7.0. This was supported by the results of best degradation rate at $\mathrm{pH}$ of 7 (Table 5). Therefore, it turns out in these data that the optimum $\mathrm{pH}$ for phenol biodegradation is 7.0 by this organism. Certainly, the enzymes have a role so that they are responsible for this degradation by $P$. fredriksbergsis cells and therefore this optimal activity is at $\mathrm{pH}$ 7.0. It has been mentioned that the optimum $\mathrm{pH}$ plays a fundamental role in the biological decomposition of these different aromatic compounds, which vary according to the type of bacteria. For example, Arthrobacter optimally biodegrade 4-CBA at optimum pH of 6.8 (Marks et al. 1984), and Halomonascampisalis biodegrade phenol and catechol at pHs range between 8 and 11 (Alva and Peyton 2003) and those for biodegradation of phenol from Klebsiellaoxytoca, it was 6.8 (Shawabkeh et al. 2007).

The results of $P$. fredriksbergsis were similar to that of Pseudomonas sp. BZD-33 (Ke et al. 2019), Pseudomonas aeruginosa PDM (Youssef et al. 2019), Rhodococcus UKMP-5M (Suhaila et al. 2019). It has been observed that many of the oxygenase enzymes and the bacteria that harbor them are able to biodegrade different types of aromatic compounds as a substrate (Khleifat 2007; Khleifat et al. 2019; Zou et al. 2018; Mohite 2015; Aravind et al. 2020). It should be
Table 5. Effect of growth conditions on the biodegradation rate of phenol by $P$. fredriksbergensis

\begin{tabular}{|c|c|c|}
\hline Condition & Value & $\begin{array}{c}\text { Biodegradation } \\
\text { rate }(\mathrm{ppm} / \mathrm{h})\end{array}$ \\
\hline \multirow{3}{*}{$\begin{array}{c}\text { Incubate } \\
\text { temperature }\left({ }^{\circ} \mathrm{C}\right)\end{array}$} & 25 & 10 \\
\cline { 2 - 3 } & 28 & 20.8 \\
\cline { 2 - 3 } & 33 & 15 \\
\hline \multirow{3}{*}{$\mathrm{pH}$} & 37 & 14.2 \\
\cline { 2 - 3 } & 5.5 & 15 \\
\cline { 2 - 3 } & 7 & 24.16 \\
\cline { 2 - 3 } & 8 & 12.5 \\
\hline
\end{tabular}

noted that many previous studies emphasized the necessity of providing an optimal amount of carbon and nitrogen sources such as yeast extract, to obtain the maximal rate of biodegradation of phenol or any other organic compounds. The reason for reasonable high degradation rate of phenol by $P$. fredriksbergsis cells can be attributed to the fact that phenol is the only carbon source and possibly the amount of phenol-degrading enzymes is sufficiently large. Besides, the bacterium is capable of devouring this substrate readily, so the potential usual attenuation of phenol toxicity is efficiently enhanced (Khleifat et al. 2006a; Khleifat et al. 2006b; Khleifat et al. 2006c; Abboud et al. 2007; Wen et al. 2020; Samadi et al. 2020; Rughöft et al. 2020).

\section{GC-MS analysis of phenol degradation}

In general, the degradation of the phenol compound by bacterial culture showed two degradation pathways. Phenol was converted to catechol by hydroxylase enzyme using a molecular oxygen to produce catechol in the first step, further degradation of the catechol by further degradation of the catechol by 1,2-dioxygenase produces a cis, cis-mucconic acid via ortho-pathway and/ or by 2,3-dioxygenase into 2-hydroxymucconic semialdehyde via meta-pathway (Das et al. 2016; Zhao et al. 2021). Figure 4 shows the presence of more than 10 peaks at different retention times. The GC-MS analysis (Figure 4) for those main peaks shows the degradation and condensation products of the catechol and/or phenol, which identified by using the NIST mass spectral data base as the following: Characterization of the decomposition product 5-methylfuran-2-ol (1) at ( $\mathrm{RT}=4.797 \mathrm{~min}$ and $\mathrm{m} / \mathrm{z}=97$ ) indicates that the phenol undergoes a repositioning in the reaction 

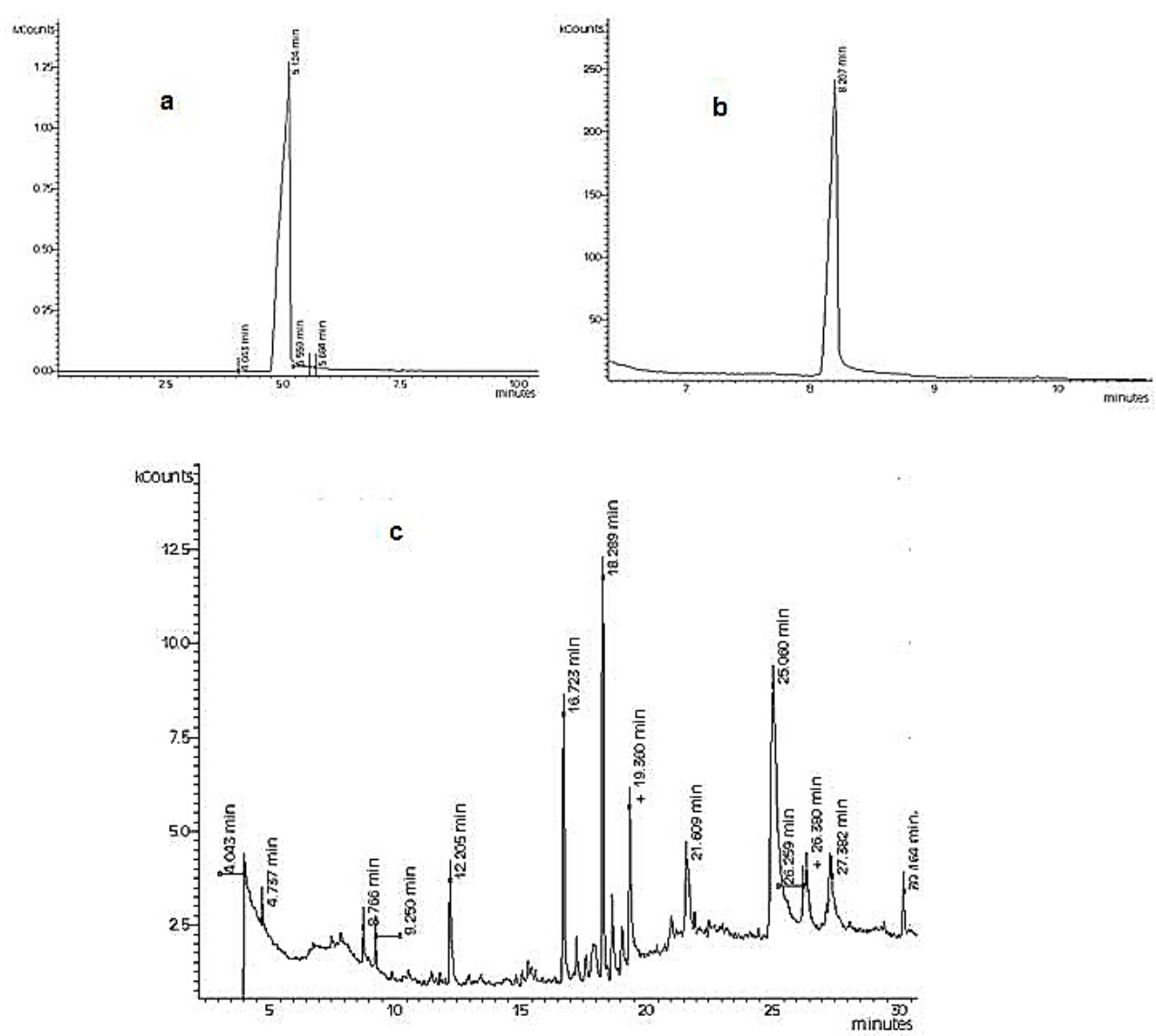

Figure 4. GC-MS chromatograms for the sample (a) control ( phenol), (b) catechol (standard), (c) sample
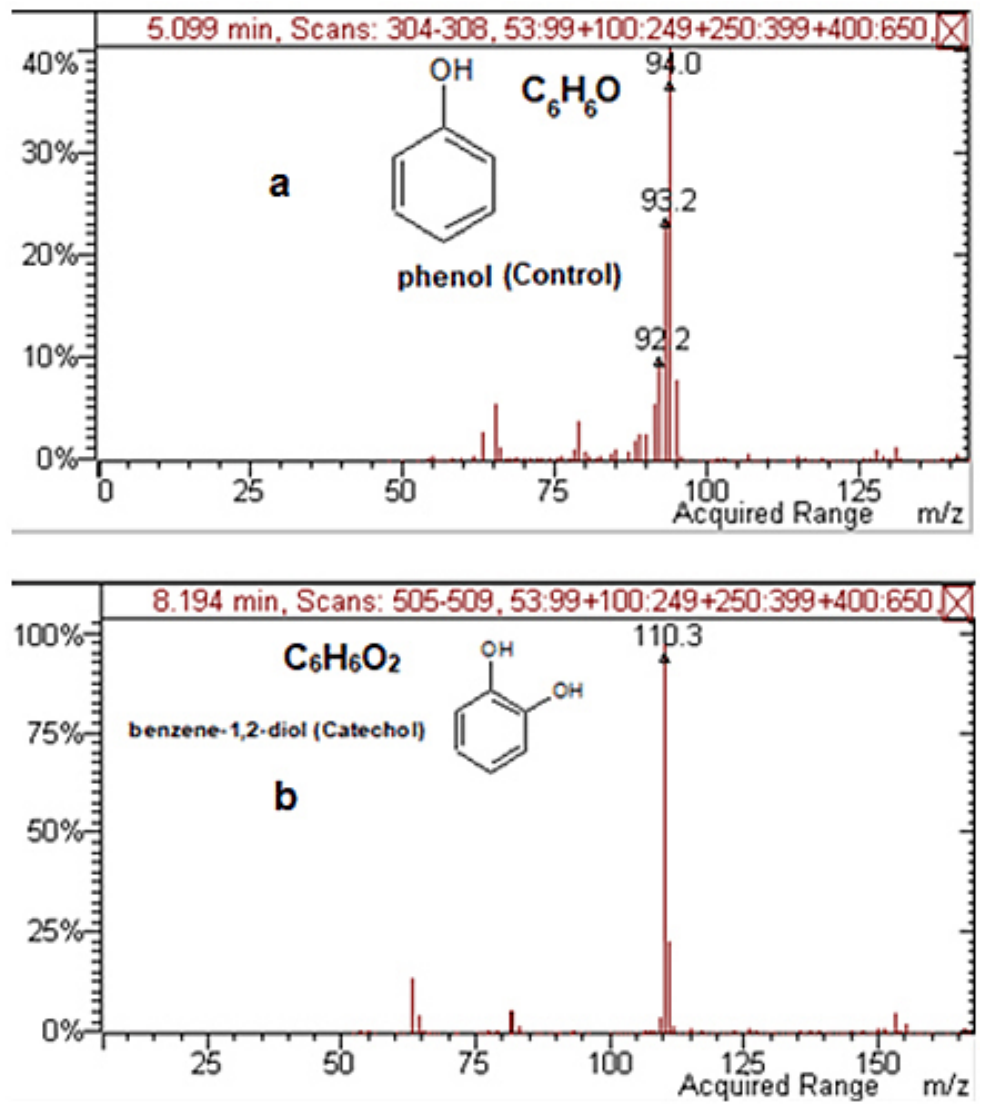

Figure 5. The fragmentation pattern of the significant peaks detected in the GC-MS analysis ,(a) phenol(control) (b) catechol (standard) 

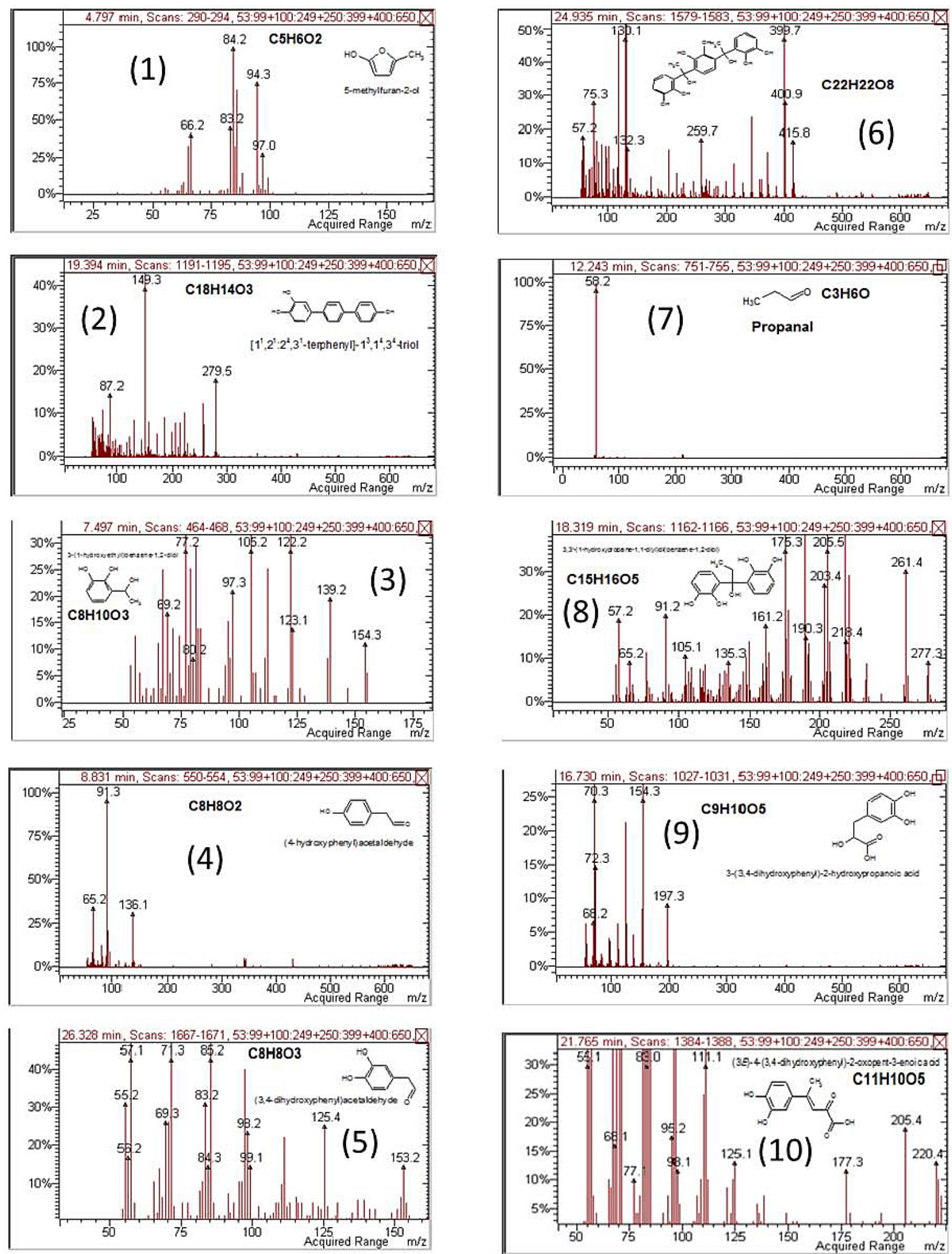

Figure 6. The fragmentation pattern of the significant peaks detected in the GC-MS analysis, and the putative chemical structure for predicted compounds (1-10)

order and confirmed that the catechol cleavage was carried out by catechol-1, 2-dioxygenase. Figure 5 shows the GC-MS analysis for phenol control sample at $(\mathrm{RT}=5.099 \mathrm{~min}$, and $\mathrm{m} / \mathrm{z}=$
94.0), and standard sample of catechol at (RT $=$ $8.194 \mathrm{~min}$ and $\mathrm{m} / \mathrm{z}=110.3$ ). Figure 6 shows the GC-MS analysis of the extractable products from bacterial culture sample. 
The results showed that most of the phenol present in the growth media was converted to catechol by the enzyme hydroxylase, which provides molecular oxygen as a first step (Das et al. 2016; Barik et al. 2021). Further degradation of the catechol by either 1,2-dioxygenase or 2,3-dioxygenase produces either a cis, cis-mucconic acid via ortho-pathway or 2-hydroxymucconic semialdehyde via meta-pathway, respectively. In addition, all intermediate products produced from the two degradative pathways undergo further multistep oxidation to produce beta-ketoadipate in the ortho pathway and/or acetaldehyde and pyruvate in the meta pathway, which are degraded to carbon dioxide and water. However, in this study sample, it was not possible to detect such compounds due to their rapid use by bacteria.

The phenol degradation pathway in Figure 7 showed that catechol, acetaldehyde and propanal could be formed from the decomposition of a phenol substrate, giving confirmed products of rearrangement, coupling, or condensation reactions of those fragments with phenol and/or catechol and other fragments detected by GC-MS through an ortho pathway (Figure 6).
The coupling of phenol and catechol [11,21:24,31-terphenyl]-13,14,34-triol (2) at (RT $=19.394 \mathrm{~min}$, and $\mathrm{m} / \mathrm{z}=279.5$ ). On other hand, the condensation of the acetaldehyde with phenol and/or catechol produced3-(1-hydroxyethyl) benzene-1,2-diol (3) at (RT= $7.497 \mathrm{~min}$, and $\mathrm{m} / \mathrm{z}$ $=154.3$ ), (4-hydroxyphenyl) acetaldehyde (4) at $(\mathrm{RT}=8.831 \mathrm{~min}$, and $\mathrm{m} / \mathrm{z}=136.1),(3,4$-dihydroxyphenyl)acetaldehyde (5) $(\mathrm{RT}=26.328$, and $\mathrm{m} / \mathrm{z}=153.2)$ and (6) $(\mathrm{RT}=24.935 \mathrm{~min}$, and $\mathrm{m} / \mathrm{z}=$ 415.8 ) as shown in Figure 6. The following product of the degradation sample produced a propanal (7) at $(\mathrm{RT}=12.243 \mathrm{~min}$, and $\mathrm{m} / \mathrm{z}=58.2)$. The condensation of the propanal with phenol and/or catechol produced a 3,3'-(1-hydroxypropane-1,1-diyl) di(benzene-1,2-diol) (8) at (RT=18.319 $\mathrm{min}$ and $\mathrm{m} / \mathrm{z}$ $=277.3$ ), as shown in Figure 6. Other condensation and elimination products are also confirmed such as, 3-(3,4-dihydroxyphenyl)-2-hydroxypropanoic acid (9) at (RT = $16.730 \mathrm{~min}$ and $\mathrm{m} / \mathrm{z}=197.3)$ and (3E)-4-(3,4-dihydroxyphenyl)-2-oxopent-3-enoic $\operatorname{acid}(10)$ at $(\mathrm{RT}=21.765 \mathrm{~min}$ and $\mathrm{m} / \mathrm{z}=220.4)$. All those products from degradation and condensation confirm that catechol cleavage takes place through meta pathway (catechol-2,3-dioxygenase).

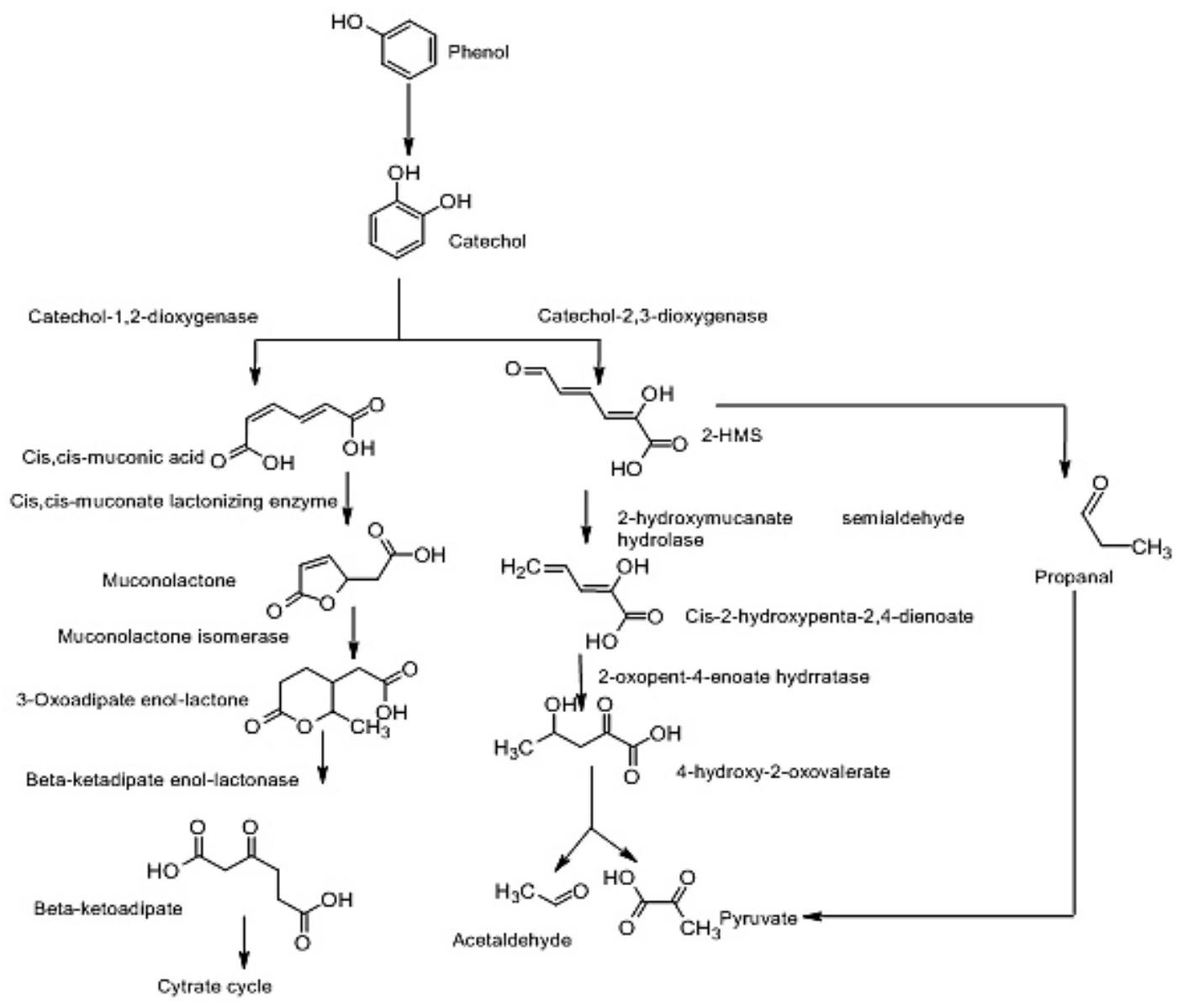

Figure 7. The putative biodegradation pathway for phenol 


\section{CONCLUSIONS}

The degradation of phenol by $P$. fredriksbergsis was investigated under different growth conditions.. Culture conditions significantly affected the cells' ability to biodegrade phenol. The highest biodegradation level of phenol and optimum organism growth could be obtained at $\mathrm{pH} 7$, temperature $28^{\circ} \mathrm{C}$, and incubation time of 36 and $96 \mathrm{~h}$. The highest biodegradation rate was perceived at $700 \mathrm{mg} / \mathrm{L}$ initial phenol concentration. The Haldane model best fitted the relationship between the specific growth rate and the initial phenol concentration. The phenol biodegradation profiles with time could be adequately described by the modified Gompertz model. The parameters of the Haldane equation are: $0.062 \mathrm{~h}^{-1}, 11 \mathrm{ppm}$, and $121 \mathrm{ppm}$ for Haldane's maximum specific growth rate, the half-saturation coefficient, and the Haldane's growth kinetics inhibition coefficient, respectively.

\section{REFERENCES}

1. Abboud M.M., Aljundi I.H., Khleifat K.M., Dmour S. 2010. Biodegradation kinetics and modeling of whey lactose by bacterial hemoglobin VHb-expressing Escherichia coli strain. Biochemical Engineering Journal, 48, 166-172.

2. Abboud M.M., Khleifat K.M., Batarseh M., Tarawneh K.A., Al-Mustafa A., Al-Madadhah M. 2007. Different optimization conditions required for enhancing the biodegradation of linear alkylbenzosulfonate and sodium dodecyl sulfate surfactants by novel consortium of Acinetobacter calcoaceticus and Pantoea agglomerans. Enzyme Microbial Technology, 41, 432-439.

3. Adetitun D.O., Akinbowale A.O., Dutta K. 2021. Biodegradation of phenol by a newly isolated Pseudomonas sp. strain B1 from tiger nuts. Covenant Journal of Physical and Life Sciences, 8.

4. Aisami A., Yasid N.A., Abd Shukor M.Y. 2020. Optimization of Cultural and Physical Parameters for Phenol Biodegradation by Newly Identified Pseudomonas sp. AQ5-04. Journal of Tropical Life Science, 10, 223-233.

5. Al-Asoufi A., Khlaifat A., Tarawneh A., Alsharafa K., Al-Limoun M., Khleifat K. 2017. Bacterial Quality of Urinary Tract Infections in Diabetic and Non Diabetics of the Population of Ma'an Province, Jordan. Pakistan Journal of Biological Sciences, 20, 179-188.

6. Althunibat O.Y., Qaralleh H., Al-Dalin S.Y.A., Abboud M., Khleifat K., Majali I.S., Aldal'in H.,
Rayyan W.A., Jaafraa A. 2016. Effect of thymol and carvacrol, the major components of Thymus capitatus on the growth of Pseudomonas aeruginosa. Journal of Pure and Applied Microbiology, 10, 367-374.

7. Alva V.A., Peyton B.M. 2003. Phenol and catechol biodegradation by the haloalkaliphile Halomonas campisalis: influence of $\mathrm{pH}$ and salinity. Environmental Science and Technology, 37, 4397-4402.

8. Andersen S.M., Johnsen K., Sørensen J., Nielsen P., Jacobsen C.S. 2000. Pseudomonas frederiksbergensis sp. nov., isolated from soil at a coal gasification site. International Journal of Systematic Evolutionary Microbiology, 50, 1957-1964.

9. Aravind M.K., Kappen J., Varalakshmi P., John S.A., Ashokkumar B. 2020. Bioengineered Graphene Oxide Microcomposites Containing Metabolically Versatile Paracoccus sp. MKU1 for Enhanced Catechol Degradation. ACS Omega, 5, 16752-16761.

10. Bakhshi Z., Najafpour G., Kariminezhad E., Pishgar R., Mousavi N., Taghizade T. 2011. Growth kinetic models for phenol biodegradation in a batch culture of Pseudomonas putida. Environmental Technology, 32, 1835-1841.

11. Barik M., Das C.P., Verma A.K., Sahoo S., Sahoo N.K. 2021. Metabolic profiling of phenol biodegradation by an indigenous Rhodococcus pyridinivorans strain PDB9T N-1 isolated from paper pulp wastewater. International Biodeterioration and Biodegradation, 158, 105168.

12. Das B., Mandal T.K., Patra S. 2016. Biodegradation of phenol by a novel diatom BD1IITG-kinetics and biochemical studies. International Journal of Environmental Science and Technology, 13, 529-542.

13. Der Yang R., Humphrey A.E. 1975. Dynamic and steady state studies of phenol biodegradation in pure and mixed cultures. Biotechnology and Bioengineering, 17, 1211-1235.

14. El-Naas M.H., Al-Zuhair S., Makhlouf S. 2010. Batch degradation of phenol in a spouted bed bioreactor system. Journal of Industrial and Engineering Chemistry, 16, 267-272.

15. Gong Y., Ding P., Xu M.-J., Zhang C.-M., Xing K., Qin S. 2021. Biodegradation of phenol by a halotolerant versatile yeast Candida tropicalis SDP-1 in wastewater and soil under high salinity conditions. Journal of Environmental Management, 289, 112525.

16. Kanavaki I., Drakonaki A., Geladas E.D., Spyros A., Xie H., Tsiotis G. 2021. Polyhydroxyalkanoate (PHA) Production in Pseudomonas sp. phDV1 Strain Grown on Phenol as Carbon Sources. Microorganisms, 9, 1636.

17. Ke Z., Xiangling W., Jian C., Jia C. 2019. Biodegradation of diethyl phthalate by Pseudomonas sp. BZD-33 isolated from active sludge', IOP Conference Series: Earth and Environmental Science. IOP Publishing. 
18. Khleifat K., Abboud M., Al-Shamayleh W., Jiries A., Tarawneh K. 2006a. Effect of chlorination treatment on gram negative bacterial composition of recycled wastewater. Pakistan Journal of Biological Sciences, 9, 1660-1668.

19. Khleifat K. \& Abboud M.M. 2003. Correlation between bacterial haemoglobin gene (vgb) and aeration: their effect on the growth and $\alpha$-amylase activity in transformed Enterobacter aerogenes. Journal of Applied Microbiology, 94, 1052-1058.

20. Khleifat K.M. 2007. Biodegradation of phenol by Actinobacillus sp.: Mathematical interpretation and effect of some growth conditions. Bioremediation Journal, 11, 103-112.

21. Khleifat K.M., Abboud M.M., Al-Mustafa A.H., AlSharafa K.Y. 2006b. Effects of carbon source and Vitreoscilla hemoglobin $(\mathrm{VHb})$ on the production of $\beta$-galactosidase in Enterobacter aerogenes. Current Microbiology, 53, 277-281.

22. Khleifat K.M., Abboud M.M., Omar S.S., Al-Kurishy J.H. 2006c. Urinary tract infection in South Jordanian population. Journal of Medical Sciences, 6, 5-11.

23. Khleifat K.M., Al-Limoun M.O., Alsharafa K.Y., Qaralleh H., Al Tarawneh A.A. 2019. Tendency of using different aromatic compounds as substrates by 2, 4-DNT dioxygenase expressed by pJS39 carrying the gene dntA from Burkholderia sp. strain DNT. Bioremediation Journal, 23, 22-31.

24. Khleifat K.M., Shawabkeh R., Al-Majali I., Tarawneh K. 2007. Biodegradation kinetics of phenol by Klebsiella oxytoca: effect of carbon and Nitrogen source. Fresenius Environmental Bulletin, 16, 489-494.

25. Khleifat K.M., Tarawneh K.A., Wedyan M.A., AlTarawneh A.A., Al Sharafa K. 2008. Growth kinetics and toxicity of Enterobacter cloacae grown on linear alkylbenzene sulfonate as sole carbon source. Current Microbiology, 57, 364-370.

26. Kumaran P. \& Paruchuri Y.L. 1997. Kinetics of phenol biotransformation. Water Research, 31, 11-22.

27. Leven L. \& Schnürer A. 2005. Effects of temperature on biological degradation of phenols, benzoates and phthalates under methanogenic conditions. International Biodeterioration and Biodegradation, 55, 153-160.

28. Lin Y.-H. \& Gu Y.-J. 2021. Biodegradation Kinetic Studies of Phenol and p-Cresol in a Batch and Continuous Stirred-Tank Bioreactor with Pseudomonas putida ATCC 17484 Cells. Processes, 9, 133.

29. Liu J., Wang Q., Yan J., Qin X., Li L., Xu W., Subramaniam R., Bajpai R.K. 2013. Isolation and characterization of a novel phenol degrading bacterial strain WUST-C1. Industrial and Engineering Chemistry Research, 52, 258-265.
30. Liu Y.J., Zhang A.N., Wang X.C. 2009. Biodegradation of phenol by using free and immobilized cells of Acinetobacter sp. XA05 and Sphingomonas sp. FG03. Biochemical Engineering Journal, 44, 187-192.

31. Malhotra M., Gupta D., Sahani J., Singh S. 2021. Microbial Degradation of Phenol and Phenolic Compounds, Recent Advances in Microbial Degradation. Springer.

32. Margesin R. \& Schinner F. 1997. Bioremediation of diesel-oil-contaminated alpine soils at low temperatures. Applied Microbiology and Biotechnology, 47, 462-468.

33. Marks T.S., Smith A.R.W., Quirk A.V. 1984. Degradation of 4-chlorobenzoic acid by Arthrobacter sp. Applied Environmental Microbiology, 48, 1020-1025.

34. Mohite B.V. 2015. Efficient Biotransformation Of Phenol And Its Derivatives Using Streptococcus Epidermis By Catechol 2, 3-Dioxygenase Metabolism. Environmental Engineering and Management Journal, 14.

35. Nandy S., Arora U., Tarar P., Viggor S., Jõesaar M., Kivisaar M., Kapley A. 2021. Monitoring the growth, survival and phenol utilization of the fluorescenttagged Pseudomonas oleovorans immobilized and free cells. Bioresource Technology, 338, 125568.

36. Onysko K.A., Budman H.M., Robinson C.W. 2000. Effect of temperature on the inhibition kinetics of phenol biodegradation by Pseudomonas putida Q5. Biotechnology and Bioengineering, 70, 291-99.

37. Pawlowsky U. \& Howell J.A. 1973. Mixed culture biooxidation of phenol. I. Determination of kinetic parameters. Biotechnology and Bioengineering, 15, 889-896.

38. Qaralleh H., Khleifat K.M., Al-Limoun M.O., Alzedaneen F.Y., Al-Tawarah N. 2019. Antibacterial and synergistic effect of biosynthesized silver nanoparticles using the fungi Tritirachium oryzae W5H with essential oil of Centaurea damascena to enhance conventional antibiotics activity. Advances in Natural Sciences: Nanoscience and Nanotechnology, 10, 025016.

39. Rai A., Gowrishetty K.K., Singh S., Chakrabarty J., Bhattacharya P., Dutta S. 2021. Simultaneous Bioremediation of Cyanide, Phenol, and Ammoniacal$\mathrm{N}$ from Synthetic Coke-Oven Wastewater Using Bacillus sp. NITD 19. Journal of Environmental Engineering, 147, 04020143.

40. Rughöft S., Vogel A.L., Joye S.B., Gutierrez T., Kleindienst S. 2020. Starvation-dependent inhibition of the hydrocarbon degrader Marinobacter sp. TT1 by a chemical dispersant. Journal of Marine Science and Engineering, 8, 925.

41. Samadi A., Sharifi H., Nejad Z.G., Hasan-Zadeh A., Yaghmaei S. 2020. Biodegradation of 4-Chlorobenzoic 
Acid by Lysinibacillus macrolides DSM54T and Determination of Optimal Conditions. International Journal of Environmental Research, 1-10.

42. Saravanan P., Pakshirajan K., Saha P. 2011. Biodegradation kinetics of phenol by predominantly Pseudomonas sp. in a batch shake flask. Desalination and Water Treatment, 36, 99-104.

43. Shawabkeh R., Khleifat K.M., Al-Majali I., Tarawneh K. 2007. Rate of biodegradation of phenol by Klebsiella oxytoca in minimal medium and nutrient broth conditions. Bioremediation Journal, 11, 13-19.

44. Suhaila Y.N., Hasdianty A., Maegala N.M., Aqlima A., Hazwan A.H., Rosfarizan M., Ariff A.B. 2019. Biotransformation using resting cells of Rhodococcus UKMP-5M for phenol degradation. Biocatalysis and Agricultural Biotechnology, 21, 101309.

45. Swain G., Sonwani R.K., Giri B.S., Singh R.S., Jaiswal R.P., Rai B.N. 2021. A study of external mass transfer effect on biodegradation of phenol using low-density polyethylene immobilized Bacillus flexus GS1 IIT (BHU) in a packed bed bioreactor. Water and Environment Journal, 35, 285-294.

46. Tarawneh K.A., Al-Tawarah N.M., Abdel-Ghani A.H., Al-Majali A.M., Khleifat K.M. 2009. Characterization of verotoxigenic Escherichia coli (VTEC) isolates from faeces of small ruminants and environmental samples in Southern Jordan. Journal of Basic Microbiology, 49, 310-317.

47. Tomei M.C., Angelucci D.M., Clagnan E., Brusetti L. 2021. Anaerobic biodegradation of phenol in wastewater treatment: achievements and limits. Applied Microbiology and Biotechnology, 1-30.

48. Wang S.-J., Loh K.-C. 1999. Modeling the role of metabolic intermediates in kinetics of phenol biodegradation. Enzyme and Microbial Technology, $25,177-184$.

49. Wen Y., Li C., Song X., Yang Y. 2020. Biodegradation of Phenol by Rhodococcus sp. Strain SKC: Characterization and Kinetics Study. Molecules, 25, 3665 .

50. Youssef M., El-Shatoury E.H., Ali S.S., El-Taweel G.E. 2019. Enhancement of phenol degradation by free and immobilized mixed culture of Providencia stuartii PL4 and Pseudomonas aeruginosa PDM isolated from activated sludge. Bioremediation Journal, 23, 53-71.

51. Zang T., Wu H., Yan B., Zhang Y., Wei C. 2021. Enhancement of PAHs biodegradation in biosurfactant/phenol system by increasing the bioavailability of PAHs. Chemosphere, 266, 128941.

52. Zhao T., Gao Y., Yu T., Zhang Y., Zhang Z., Zhang L., Zhang L. 2021. Biodegradation of phenol by a highly tolerant strain Rhodococcus ruber $\mathrm{C} 1$ : Biochemical characterization and comparative genome analysis. Ecotoxicology and Environmental Safety, 208, 111709.

53. Zou S., Zhang B., Yan N., Zhang C., Xu H., Zhang Y., Rittmann B.E. 2018. Competition for molecular oxygen and electron donor between phenol and quinoline during their simultaneous biodegradation. Process Biochemistry, 70, 136-143. 